\title{
Color stability of ceramic brackets immersed in potentially staining solutions
}

\author{
Bruna Coser Guignoneㄹ, Ludimila Karsbergen Silva¹, Rodrigo Villamarim Soares², Emilio Akaki², \\ Marcelo Coelho Goiato ${ }^{3}$, Matheus Melo Pithon ${ }^{4}$, Dauro Douglas Oliveira ${ }^{5}$
}

DOI: http://dx.doi.org/10.1590/2176-9451.20.4.032-038.oar

\begin{abstract}
Objective: To assess the color stability of five types of ceramic brackets after immersion in potentially staining solutions. Methods: Ninety brackets were divided into 5 groups $(\mathrm{n}=18)$ according to brackets commercial brands and the solutions in which they were immersed (coffee, red wine, coke and artificial saliva). The brackets assessed were Transcend (3M/ Unitek, Monrovia, CA, USA), Radiance (American Orthodontics, Sheboygan, WI, USA), Mystique (GAC International Inc., Bohemia, NY, USA) and Luxi II (Rocky Mountain Orthodontics, Denver, CO, USA). Chromatic changes were analyzed with the aid of a reflectance spectrophotometer and by visual inspection at five specific time intervals. Assessment periods were as received from the manufacturer $\left(\mathrm{T}_{0}\right), 24$ hours $\left(\mathrm{T}_{1}\right), 72$ hours $\left(\mathrm{T}_{2}\right)$, as well as 7 days $\left(\mathrm{T}_{3}\right)$ and 14 days $\left(\mathrm{T}_{4}\right)$ of immersion in the aforementioned solutions. Results were submitted to statistical analysis with ANOVA and Bonferroni correction, as well as to a multivariate profile analysis for independent and paired samples with significance level set at 5\%. Results: The duration of the immersion period influenced color alteration of all tested brackets, even though these changes could not always be visually observed. Different behaviors were observed for each immersion solution; however, brackets immersed in one solution progressed similarly despite minor variations. Conclusions: Staining became more intense over time and all brackets underwent color alterations when immersed in the aforementioned solutions.
\end{abstract}

Keywords: Orthodontic brackets. Optical properties. Color instability.

Objetivo: avaliar a estabilidade da cor de cinco tipos de braquetes cerâmicos após imersão em soluções potencialmente corantes. Métodos: noventa braquetes foram divididos em 5 grupos $(n=18)$ de acordo com a marca comercial dos braquetes e as soluções em que foram imersos (café, vinho tinto, Coca-Cola e saliva artificial). Os baquetes avaliados foram Transcend (3M / Unitek, Monrovia, CA, EUA), Radiance (American Ortodontia, Sheboygan, WI, EUA), Mystique (GAC International Inc., Bohemia, NY, EUA) e Luxi II (Rocky Mountain Orthodontics, Denver, CO, EUA). Alterações cromáticas foram analisadas com o uso de um espectrofotômetro de reflectância e por inspecção visual, em cinco intervalos de tempo específicos. Os momentos de avaliação foram: 24 horas $\left(\mathrm{T}_{1}\right), 72$ horas $\left(\mathrm{T}_{2}\right), 7$ dias $\left(\mathrm{T}_{3}\right)$ e $14 \operatorname{dias}\left(\mathrm{T}_{4}\right)$ de imersão nas soluções. Os resultados foram submetidos à avaliação estatística com análise de variância e correção de Bonferroni, bem como a uma análise do perfil multivariada para amostras independentes e pareadas, com nível de significância de 5\%. Resultados: a duração do período de imersão influenciou na alteração de cor de todos os braquetes testados, mesmo admitindo-se que essas alterações nem sempre puderam ser observadas visualmente. Diferentes comportamentos foram observados em cada solução de imersão; no entanto, braquetes imersos em um mesmo tipo de solução progrediram de forma semelhante, apesar das pequenas variações. Conclusões: a coloração se tornou mais intensa com o tempo, e todos os braquetes sofreram alteração de cor nas soluções imersas.

Palavras-chave: Braquetes ortodônticos. Propriedades ópticas. Instabilidade de cor.

${ }^{1} \mathrm{MSc}$ in Orthodontics, Pontifícia Universidade Católica de Minas Gerais (PUC Minas), Belo Horizonte, Minas Gerais, Brazil.

${ }^{2}$ Associate professor, Pontifícia Universidade Católica de Minas Gerais (PUC Minas), Belo Horizonte, Minas Gerais, Brazil.

${ }^{3}$ Full professor, Universidade Estadual Paulista Júlio de Mesquita

Filho (UNESP), Araçatuba, São Paulo, Brazil.

${ }^{4}$ Adjunct professor of Orthodontics, Universidade Estadual do Sudoeste da Bahia (UESB), Jequié, Bahia, Brazil.

${ }^{5}$ Director of Orthodontics Program, Pontifícia Universidade Católica de Minas Gerais (PUC Minas), Belo Horizonte, Minas Gerais, Brazil.
How to cite this article: Guignone BC, Silva LK, Soares RV, Akaki E, Goiato MC, Pithon MM, Oliveira DD. Color stability of ceramic brackets immersed in potentially staining solutions. Dental Press J Orthod. 2015 JulyAug;20(4):32-8. DOI: http://dx.doi.org/10.1590/2176-9451.20.4.032-038.oar

Submitted: January 2, 2014 - Revised and accepted: November 1, 2014

Contact address: Dauro Douglas Oliveira

Av. Dom José Gaspar, 500 - Prédio 46, Sala 106

Belo Horizonte, MG, Brazil, CEP: 30535-610 - E-mail: dauro.bhe@gmail.com 


\section{INTRODUCTION}

The increasing number of adult patients seeking orthodontic treatment has reinforced the need for esthetic orthodontic appliances. ${ }^{1}$ The orthodontic industry, aiming to profit from this demand, has invested in the development of different types of esthetic material, striving to meet the expectations of patients and clinicians. ${ }^{1,2} \mathrm{Ce}-$ ramic brackets are a result os this process. ${ }^{3,4}$

Ceramic brackets may be manufactured with polycrystalline ceramic or monocrystalline sapphire. ${ }^{3,45}$ These brackets are inert to the oral environment ${ }^{1}$ and have become the most commonly used esthetic fixed orthodontic appliances worldwide due to superior esthetics and mechanical resistance when compared to plastic brackets. ${ }^{1,3-6}$

Despite remarkable quality improvement since the introduction of the first ceramic brackets in the 80's, ceramic brackets currently available on the market still present significant limitations, such as high friability; increased friction with orthodontic wires, when compared to metallic brackets; the possibility of causing wear on antagonist teeth; and the risk of damaging the enamel structure during debonding. ${ }^{7,8}$ Although their color features are their major advantage over metallic brackets, there is a limited number of reports analyzing their optical properties over time. ${ }^{10}$ Lack of such studies may be related to technical difficulties in measuring brackets color, given that their geometry may hinder accurate color measurement with a spectrophotometer or colorimeter. ${ }^{12}$

Therefore, the objective of this study was to assess the color stability of different ceramic brackets exposed to potentially staining solutions during a period of time.

\section{MATERIAL AND METHODS}

Ninety maxillary central incisor ceramic brackets of five different types and commercial brands (Table 1) were assessed $(n=18)$. Prior to immersion in potentially staining solutions, all brackets had their bases leveled by 180-grain water sandpapers (Doble $\mathrm{A}^{\circledR}$, Argentine Abrasives S.A.I.C, Argentina) in a polishing machine (Knuth-Rotor ${ }^{\circledR}$, Struers, Denmark) under constant irrigation. Subsequently, all brackets were cleaned with acetone to remove any speck adhered to their surface.

\section{Staining analysis}

Brackets were immersed in four potentially staining solutions: red wine (Miolo Terranova 2006, Bento Gonçalves, Brazil), coffee (Café Três Corações, Três Corações, Brazil), coke (Coca-Cola, Belo Horizonte, Brazil) and artificial saliva (control group). Each solution was distributed into five small black plastic containers, so as to eliminate light interference. Each container had six brackets of the same brand and was stored at room temperature. Solutions were changed every 24 hours. All brackets were divided into four groups, according to the solution in which they were immersed $(n=6)$.

Before immersion $\left(\mathrm{T}_{0}\right)$, all brackets had color measured (baseline $-\mathrm{T}_{0}$ ). Subsequently, color was analyzed after a period of $24\left(\mathrm{~T}_{1}\right)$, and 72 hours $\left(\mathrm{T}_{2}\right)$, as well as after $7\left(\mathrm{~T}_{3}\right)$ and 14 days $\left(\mathrm{T}_{4}\right)$ of immersion.

Color readings were assessed with the aid of a reflectance spectrophotometer (UV-visible spectrophotometer UV-2450, Shimadzu, Kyoto, Japan), according to the Commission Internationale de $1^{\prime}$ Eclairage (CIE) $\mathrm{L}^{\star}, \mathrm{a}^{\star}, \mathrm{b}^{\star}$ (LAB) color scale. ${ }^{15}$ The CIELAB system of color assessment quantitatively assess the color features of an object, based on three parameters $\left(L^{\star}, a^{\star} e b^{\star}\right): L^{\star}$ is the measurement of brightness quantified on a scale in which black has an $L^{\star}$ value equal to zero, whereas a totally reflected light has an $\mathrm{L}^{\star}$ value equal to 100 ; $\mathrm{a}^{\star}$ measures the amount of red $\left(+a^{\star}\right)$ and green $\left(-a^{\star}\right)$; and $b^{\star}$ measures the amount of yellow $\left(+b^{\star}\right)$ and blue $\left(-b^{\star}\right)$. Total color

Table 1 - Ceramic brackets evaluated.

\begin{tabular}{ccc}
\hline Commercial brand & Composition & Manufacturer \\
Clarity & Polycrystalline alumina, stainless steel slot & $3 M /$ Unitek, Monrovia, CA, USA \\
Transcend & Polycrystalline alumina & $3 M /$ Unitek, Monrovia, CA, USA \\
Radiance & Monocrystalline alumina & American Orthodontics, Sheboygan, WI, USA \\
Mystique & Polycrystalline alumina & GAC International Inc., Bohemia, NY, USA \\
Luxi II & Polycrystalline alumina, gold slot & Rocky Mountain Orthodontics, Denver, CO, USA \\
\hline
\end{tabular}


changes $\left(\Delta E^{\star} a b\right)$ were calculated by the following equation: ${ }^{16} \Delta \mathrm{E}^{\star} \mathrm{ab}=\left[\left(\Delta \mathrm{L}^{\star}\right)^{2}+\left(\Delta \mathrm{a}^{\star}\right)^{2}+\left(\Delta \mathrm{b}^{\star}\right)^{2}\right]^{1 / 2}$.

Changes in color parameters $\left(\Delta \mathrm{L}^{\star}, \Delta \mathrm{a}^{\star}\right.$ and $\left.\Delta \mathrm{b}^{\star}\right)$ were calculated by subtraction (i.e. $\mathrm{T}_{1}-\mathrm{T}_{0}$ ). Prior to each measurement carried out with the reflectance spectrophotometer, all brackets were washed with distilled water, so as to remove any staining solution residue from their surface.

\section{Visual assessment}

Visual analysis of brackets was performed at the same time intervals previously described and by two different operators. One bracket from each group was washed with distilled water, air-dried and placed on a white surface beside a similar bracket, which had not been immersed in any staining solution, for comparison.

This analysis aimed to visually detect potential bracket staining and relate it to the time of immersion in different solutions. Whenever any visible color change was detected, it was recorded as described by Mancuso et al. ${ }^{11}$

\section{Statistical analysis}

Data were analyzed by means of SPSS 15.0, Microsoft Excel and Gpower 3.0. Multivariate profile analysis, analysis of variance (ANOVA) and t test for independent paired samples, with significance level set at 5\%, were used to compare intra and intergroup mean values obtained in the reflectance spectrophotometer after immersion of brackets in different solutions during specific time intervals.

ANOVA was used to investigate differences between groups and when significant differences were found, Bonferroni correction was used to verify in which group such differences had occurred (Table 2). Multivariate profile analysis (Table 3) was used to analyze time effect not considering brackets brand. It was also used to test whether the staining pattern and the tested brackets brands were similar or different over time.

\section{RESULTS}

After being immersed in artificial saliva for 24 hours, Radiance brackets presented statistically significant color alteration when compared to Transcend brackets which were the most stable group (Table 2).

ANOVA results (Table 2) revealed that, when immersed in coke, Radiance brackets presented statisti- cally significant $(p<0.05)$ color alterations in comparison to other bracket brands after 24 and 72 hours, as well as after 7 days of immersion. However, there were no statistically significant differences $(p>0.05)$ regarding color changes between brackets brands in this solution after 14 days (Table 2). Immersion in coffee only caused statistically significant color alterations in Transcend brackets compared to Mystique brackets after 14 days of immersion (Table 2). When immersed in red wine for 24 hours, Radiance brackets presented statistically higher $(p<0.05)$ color alterations in comparison to Luxi II. The same interval of red wine immersion promoted statistically higher $(p<0.05)$ color alterations in Radiance brackets in comparison to Clarity, Luxi II and Transcend brackets. However, after 72 hours, the color alterations observed in Radiance brackets were only higher than Luxi II brackets (Table 2), and differences between bracket brands after this period of immersion were not found.

Multivariate analysis results (Table 3 ) revealed that, during a specific time period (from 7 to 14 days), there were significant color changes $(p=0.000)$ in all brackets immersed in coke. Immersion in the same solution led to similar staining patterns after 24 to 72 hours $(p=0.486)$, and from 72 hours to 7 days $(p=0.525)$, although a different staining pattern occurred from 7 to 14 days $(p=0.002)$. A time effect $(p=0.004)$ was also observed on brackets exposed to coffee solution, since there were significant color alterations for specific time periods ( 24 to 72 hours $-p=0.007 ; 72$ hours to 7 days $-p=0.002)$. Immersion in the same solution led to a similar staining pattern on bracket brands only from 24 to 72 hours $(p=0.478)$. Finally, immersion in red wine also revealed a time effect $(p=0.000)$, since significant color alterations at all time intervals (24 to 72 hours $-p=0.000 ; 72$ hours to 7 days $-p=0.002$; 7 to 14 days $-p=0.000$ ) were observed in the brackets tested. Exposure to this solution also led to different $(p=0.004)$ staining patterns on bracket brands at all time intervals ( 24 to 72 hours, $p=0.018 ; 72$ hours to 7 days, $p=0.012 ; 7$ to 14 days, $p=0.005$ ).

\section{Visual inspection}

After seven days of immersion in staining solutions, chromatic changes were found in all types of brackets analyzed. Thereafter, there was progressive staining of brackets until 14 days of immersion. Brackets immersed 
Table 2 - Mean values of color alteration of brackets immersed in different solutions and over different periods of time.

\begin{tabular}{|c|c|c|c|c|c|}
\hline & & $\Delta E_{1}(24 h)$ & $\Delta E_{2}(72 h)$ & $\Delta E_{3}(7 d)$ & $\Delta E_{4}(14 d)$ \\
\hline \multirow{4}{*}{ Clarity } & Saliva & 126.93 & 126.93 & 126.93 & 126.93 \\
\hline & Coke & 117.53 & 104.93 & 98.06 & 46.38 \\
\hline & Coffee & 109.86 & 90.31 & 54.93 & 42.24 \\
\hline & Red wine & 40.5 & 50.84 & 72.94 & 135.31 \\
\hline \multirow{4}{*}{ Luxi II } & Saliva & 142.3 & 142.3 & 142.3 & 142.3 \\
\hline & Coke & 88.41 & 108.6 & 98.19 & 29.68 \\
\hline & Coffee & 78.16 & 48.88 & 74.13 & 58.15 \\
\hline & Red wine & 26.84 & 43.42 & 65.63 & 140.72 \\
\hline \multirow{4}{*}{ Mystique } & Saliva & 116.47 & 116.47 & 116.47 & 116.47 \\
\hline & Coke & 120.81 & 135.18 & 129.67 & 36.67 \\
\hline & Coffee & 78.19 & 67.65 & 59.67 & 37.43 \\
\hline & Red wine & $58.61^{b}$ & 65.71 & 73.39 & 112.14 \\
\hline \multirow{4}{*}{ Radiance } & Saliva & $155.07^{\mathrm{e}}$ & $155.07^{\mathrm{e}}$ & $155.07^{e}$ & $155.07^{e}$ \\
\hline & Coke & $173.45^{\text {be }}$ & $166.85^{\mathrm{abe}}$ & $175.58^{\text {abce }}$ & 55.92 \\
\hline & Coffee & 96.95 & 74.78 & 40.79 & 85.03 \\
\hline & Red wine & $80.52^{\text {abe }}$ & $75.39^{b}$ & 65.96 & 97.34 \\
\hline \multirow{4}{*}{ Transcend } & Saliva & 111.65 & 111.65 & 111.65 & 111.65 \\
\hline & Coke & 75.57 & 93.5 & 96.78 & 50.92 \\
\hline & Coffee & 44.74 & 45.6 & 44.12 & $94.18^{c}$ \\
\hline & Red wine & 40.56 & 67.13 & 61.98 & 126.09 \\
\hline
\end{tabular}

ANOVA and Bonferroni correction. Statistically significant differences $(p<0.05)$ between bracket brands are represented by letters.

Table 3 - Multivariate analysis of brackets exposed to different staining solutions: time and brand factors.

\begin{tabular}{|c|c|c|c|}
\hline & \multicolumn{3}{|c|}{ Significance } \\
\hline & Coke & Coffee & Wine \\
\hline Time (initial) & 0.000 & 0.004 & 0.000 \\
\hline 24 hours - 72 hours & 0.363 & 0.007 & 0.000 \\
\hline 72 hours - 7 days & 0.801 & 0.002 & 0.002 \\
\hline 7 days - 14 days & 0.000 & 0.650 & 0.000 \\
\hline Time by brand (parallelism) & 0.020 & 0.002 & 0.004 \\
\hline 24 hours - 72 hours & 0.486 & 0.478 & 0.018 \\
\hline 72 hours - 7 days & 0.525 & 0.009 & 0.012 \\
\hline 7 days - 14 days & 0.002 & 0.014 & 0.005 \\
\hline Brands & 0.000 & 0.424 & 0.354 \\
\hline
\end{tabular}

Coke: 1) Mauchly's sphericity test $(p=0.152) ; 2)$ non-significant Levene's test $\left[\Delta \mathrm{E}_{1}(24 \mathrm{~h})(p=0.03) ; \Delta \mathrm{E}_{2}(72 \mathrm{~h})(p=0.08) ; \Delta \mathrm{E}_{3}(7 \mathrm{~d})(p=0.22) ; \Delta \mathrm{E}_{4}(14 \mathrm{~d})(p=0.79)\right]$

Coffee: 1) Mauchly's sphericity test $(p=0.001) ; 2)$ non-significant Levene's test $\left[\Delta \mathrm{E}_{1}(24 \mathrm{~h})(p=0.58) ; \Delta \mathrm{E}_{2}(72 \mathrm{~h})(p=0.37) ; \Delta \mathrm{E}_{3}(7 \mathrm{~d})(p=0.32) ; \Delta \mathrm{E}_{4}(14 \mathrm{~d})(p=0.98)\right]$.

Wine: 1) Mauchly's sphericity test $(p<0.001) ; 2)$ non-significant Levene's test $\left[\Delta \mathrm{E}_{1}(24 \mathrm{~h})(p=0.02) ; \Delta \mathrm{E}_{2}(72 \mathrm{~h})(p=0.82) ; \Delta \mathrm{E}_{3}(7 \mathrm{~d})(p=0.97) ; \Delta \mathrm{E}_{4}(14 \mathrm{~d})(p=0.18)\right]$. 


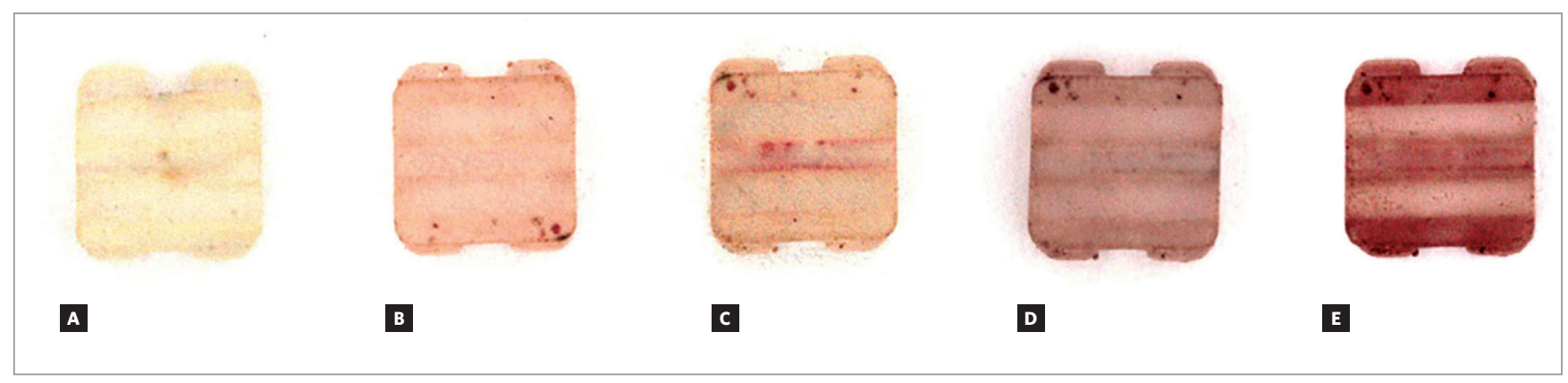

Figure 1 - Brackets after immersion in red wine: A) baseline, B) after 24 hours, C) after 72 hours, D) after 7 days, and E) after 14 days of immersion.

in artificial saliva revealed no visible color changes after 24 hours of immersion (Fig 1).

\section{DISCUSSION}

Ceramic brackets are used in Orthodontics when patients require an esthetic alternative to metallic brackets. Although color stability throughout orthodontic treatment is a very important characteristic of this type of material, ${ }^{12}$ very little is found in the literature about this property. Therefore, the aim of the present study was to assess color stability of different ceramic brackets immersed in potentially staining solutions.

Assessment of orthodontic material color stability may be performed with equipment especially designed to analyze the reflective characteristics of an object or by means of comparative visual assessment. ${ }^{12}$ Reflectance spectrophotometer and colorimeter are usually used for color analysis because these instruments provide consistent numerical evaluation of color characteristics. ${ }^{13,14}$

Previous studies have tried to correlate numeric color alteration readings $\left(\Delta \mathrm{E}^{\star}\right)$ provided by a spectrophotometer to the visual perception of staining of composite resin or prosthetic restorations. ${ }^{15-19}$ In visual perception, a threshold of color alteration reflected in esthetic restorations with a mean $\Delta \mathrm{E}^{\star}$ value greater than 2.0 is noticed by all observers, while $\Delta \mathrm{E}^{\star}$ values ranging between 1.0 and 2.0 are not often perceived. ${ }^{18}$ Nevertheless, other authors have proposed $\Delta \mathrm{E}^{\star}$ values as from $3.3^{20}$ and $3.7^{21}$ for clinical perception of color changes involving composite resin restorations. Thus, research in the orthodontic field can use these references to assess color stability of esthetic brackets and elastics.

Faltermeier et a ${ }^{22}$ investigated color stability of esthetic brackets after ultraviolet light irradiation and exposure to staining solutions. ${ }^{13}$ The authors considered $\Delta \mathrm{E}^{\star}$ mean alues $\geq 3.3$ as clinically unacceptable. However, Lee ${ }^{23}$ assessed color changes in reflected and transmitted color, in addition to color parameters of esthetic brackets after thermocycling, and suggested $\Delta \mathrm{E}^{\star}$ equal to 3.7 was the threshold for clinical perception of color alteration.

Importantly, the $\Delta \mathrm{E}^{\star}$ values used as reference in previous studies may not be compared to those used in the present study, since in addition to using different types of brackets, our spectrophotometric assessment was performed on bracket worn bases, while the others measured it on bracket buccal surfaces. Assessment on bracket buccal surface may be influenced by the shadows of the bracket slot and wings. These areas also present greater potential for accumulation of staining pigments, which may camouflage the actual staining of the ceramic brackets structure. We decided to level the bracket bases to increase the precision of spectrophotometer assessment, since this equipment was developed to analyze the characteristics of light reflected on flat surfaces.

In addition to assessment carried out with the aid of a spectrophotometer, two calibrated operators also performed a visual analysis. Staining of all ceramic brackets was observed in all three staining solutions after the seventh day of immersion. Thereafter, a progressive staining of these brackets was visually observed by the end of the 14-day period. Red wine was the solution that caused the most intense staining of all brackets tested, followed by coffee and coke, respectively. Despite presenting the lowest $\mathrm{pH}$ levels among the three staining solutions tested and potentially affecting a given material surface, coke did not cause as much color alteration as coffee and red wine, probably due to lack of yellow pigment in its composition..$^{22,25}$ 
As previously mentioned, the literature on color stability of orthodontic material is limited. ${ }^{22,25}$ However, several techniques have been described to study the staining of dental material. Methods of aging acceleration, such as thermocycling, immersion in artificial saliva, coffee, tea, grape juice and chlorhexidine, have been used in in vitro simulations. ${ }^{14}$ It has been demonstrated that the type of solution as well as total exposure time influenced the degree of color alteration of these types of material. ${ }^{26}$ These results are in accordance with our findings.

Ertas et $\mathrm{l}^{15}$ assessed color stability of five types of composite resins immersed in tea, coke, coffee, red wine and water. Similarly to the present study, these solutions were used because they are the potentially staining solutions frequently consumed by adults. The authors also established 14 days as the total immersion time due to believing it would initially resemble the environmental color stability challenge that composite resins must face in the oral cavity.

Although Radiance brackets showed greater $\Delta \mathrm{E}^{\star}$ mean values of color alteration when compared to the other brackets after 24 and 72 hours and 7 days of immersion in coke, this difference was not statistically significant after 14 days. Bracket brand staining in coffee solution was similar, since only one single statistically significant difference was detected (14 days, Transcend versus Mystique, $p=0.9418)$. After 24 hours of immersion in red wine, Mystique brackets presented with significant color alteration in comparison to Luxi II. After the same period of time, as well as after 72 hours and 7 days of immersion in this solution, Radiance brackets stood out statistically with a higher color alteration in comparison to other bracket brands (Table 2). It was also possible to observe that, in general, time significantly affected color alteration of these brackets, and the pattern of color change in specific solutions and time periods was similar or different (Table 3).

Regarding the staining potential of each solution, an interesting fact was observed. Coke, which was the solution that caused the least color alteration during visual inspection, yielded the highest $\Delta \mathrm{E}^{\star}$ values in the spectrophotometric analysis. A possible explanation for this observation is that, due to its acidic properties, this solution has the ability of altering the material surface, leading to greater absorption of coloring pigments from the solution by the porcelain, which can be detected accurately by the spectrophotometer while not detected by the human eye. In agreement with previous studies, it was visually observed in the present study that red wine caused more color alterations than coffee, which was also confirmed by the spectrophotometric analysis.

It is important to point out that these results should not be extrapolated to clinical reality, given that methodological limitations are inevitable when assessing color alterations of brackets in vitro. Reproducibility of the conditions present in the oral cavity is quite complex due to several factors, including the intricate flora and its by-products, in addition to biofilm deposition in the tested material. Therefore, further clinical studies investigating orthodontic material color stability should be conducted in order to keep up with orthodontic patients' demand.

\section{CONCLUSION}

Ceramic brackets displayed color changes after immersion in staining solutions, and the period of exposure to red wine influenced the amount of staining registered in the ceramic brackets assessed. When immersed in coke and red wine for specific periods of time, Radiance brackets generally presented statistically higher color alterations in comparison to other bracket brands.

\section{Author contributions}

Conceived and designed the study: BCG. Acquisition, analysis or interpretation: BCG. Data collection: MCG. Wrote the article: BCG, LKS, RVS, MCG. Critical revision of the article: MMP, DDO. Final approval of the article: EA, DDO. 


\section{REFERENCES}

1. Gkantidis N, Zinelis S, Karamolegkou M. Eliades T, Topouzelis N Comparative assessment of clinical performance of esthetic bracket materials. Angle Orthod. 2012;82(4):691-7.

2. Faltermeier A, Burgers R, Rosentritt M. Bacterial adhesion of Streptococcus mutans to esthetic bracket materials. Am J Orthod Dentofacial Orthop. 2008:133(4 Suppl):S99-103

3. Dostalova T, Jelinkova H, Sulc J, Nemec M, Jelinek M, Fibrich M, et al. Ceramic bracket debonding by TM: YAP laser irradiation. Photomed Laser Surg. 2011;29(7):477-84.

4. Sarp AS, Gulsoy M. Ceramic bracket debonding with ytterbium fiber laser Lasers Med Sci. 2011:26(5):577-84.

5. Falkensammer F, Freudenthaler J, Pseiner B, Bantleon HP. Influence of surface conditioning on ceramic microstructure and bracket adhesion. Eur J Orthod. 2012;34(4):498-504.

6. Pithon MM, Oliveira MV, Ruellas AC, Bolognese AM, Romano FL. Shear bond strength of orthodontic brackets to enamel under different surface treatment conditions. J Appl Oral Sci. 2007:15(2):127-30.

7. Pereira BR, Tanaka OM, Lima AA, Guariza-Filho O, Maruo H, Camargo ES Metal and ceramic bracket effects on human buccal mucosa epithelial cells. Angle Orthod. 2009:79(2):373-9

8. Bishara SE, Ostby AW, Laffoon J, Warren JJ. Enamel cracks and ceramic bracket failure during debonding in vitro. Angle Orthod. 2008;78(6):1078-83.

9. Lindauer SJ, Macon CR, Browning H, Rubenstein LK, Isaacson RJ. Ceramic bracket fracture resistance to second order arch wire activations. Am J Orthod Dentofacial Orthop. 1994;106(5):481-6

10. Ozcan M, Finnema K, Ybema A. Evaluation of failure characteristics and bond strength after ceramic and polycarbonate bracket debonding: effect of bracket base silanization. Eur J Orthod. 2008:30(2):176-82.

11. Mancuso DN, Goiato MC, Dekon SF, Gennari-Filho H. Visual evaluation of color stability after accelerated aging of pigmented and nonpigmented silicones to be used in facial prostheses. Indian J Dent Res. 2009;20(1):77-80

12. Lopes Filho H, Maia LE, Araujo MV, Ruellas AC. Influence of optical properties of esthetic brackets (color, translucence, and fluorescence) on visual perception. Am J Orthod Dentofacial Orthop. 2012;141(4):460-7.

13. Faltermeier A, Behr M, Mussig D. Esthetic brackets: the influence of filler level on color stability. Am J Orthod Dentofacial Orthop. 2007:132(1):5.e13-6.
14. Haselton DR, Diaz-Arnold AM, Dawson DV. Color stability of provisional crown and fixed partial denture resins. J Prosthet Dent. 2005:93(1):70-5

15. Ertas E, Guler AU, Yucel AC, Koprulu H, Guler E. Color stability of resin composites after immersion in different drinks. Dent Mater J. 2006:25(2):371-6

16. Drubi-Filho B, Garcia Lda F, Cruvinel DR, Sousa AB, Pires-de-Souza FC. Color stability of modern composites subjected to different periods of accelerated artificial aging. Braz Dent J. 2012:23(5):575-80

17. Bayindir F, Kurklu D, Yanikoglu ND. The effect of staining solutions on the color stability of provisional prosthodontic materials. J Dent. 2012;40 Suppl 2:e41-46.

18. Gonulol N, Yilmaz F. The effects of finishing and polishing techniques on surface roughness and color stability of nanocomposites. J Dent. 2012;40 Suppl 2:e64-70

19. Erdemir U, Yildiz E, Eren MM. Effects of sports drinks on color stability of nanofilled and microhybrid composites after long-term immersion. J Dent. 2012;40 Suppl 2:e55-63.

20. Ruyter IE, Nilner K, Moller B. Color stability of dental composite resin materials for crown and bridge veneers. Dent Mater. 1987:3(5):246-51

21. Johnston WM, Kao EC. Assessment of appearance match by visual observation and clinical colorimetry. J Dent Res. 1989;68(5):819-22.

22. Faltermeier A, Behr M, Mussig D. In vitro colour stability of aesthetic brackets. Eur J Orthod. 2007:29:354-358

23. Lee YK. Changes in the reflected and transmitted color of esthetic brackets after thermal cycling. Am J Orthod Dentofacial Orthop. 2008:133(5):641.e1-6

24. Um CM, Ruyter IE. Staining of resin-based veneering materials with coffee and tea. Quintessence Int. 1991;22(5):377-86

25. Eliades T, Kakaboura A, Eliades G, Bradley TG. Comparison of enamel colour changes associated with orthodontic bonding using two different adhesives. Eur J Orthod. 2001:23(1):85-90.

26. Yannikakis SA, Zissis AJ, Polyzois GL, Caroni C. Color stability of provisional resin restorative materials. J Prosthet Dent. 1998:80(5):533-9

27. Stober T, Gilde H, Lenz P. Color stability of highly filled composite resin materials for facings. Dent Mater. 2001:17(1):87-94

28. Khokhar ZA, Razzoog ME, Yaman P. Color stability of restorative resins. Quintessence Int. 1991;22(9):733-7. 